\title{
Ratings of perceived exertion at anaerobic threshold in patients with coronary artery disease
}

\section{Percepção subjetiva do esforço no limiar anaeróbio em pacientes com doença arterial coronariana}

Percepción subjetiva del esfuerzo en el liminar anaeróbico en pacientes con enfermedad arterial coronaria

\author{
Meire Forti ${ }^{1}$, Antonio Roberto Zamunér ${ }^{1}$, Vandeni Clarice Kunz², Mariana Rodrigues Salviati ${ }^{3}$ \\ Tarcísio Augusto Gonçalves Nery³, Ester da Silva
}

\begin{abstract}
I The study aimed to identify and compare the ratings of perceived exertion (RPE) at the ventilatory anaerobic threshold (VAT) in healthy subjects and patients with coronary artery disease (CAD). A total of 30 male subjects took part in the study and were divided into three groups: a control group (CG) composed of 10 healthy participants; a group composed of 10 participants diagnosed with CAD beta-blocker user (G-DACb); and a group composed of 10 participants with CAD non-beta-blocker user (G-DAC). The participants performed a cardiopulmonary exercise test (CPET) with continuous type ramp protocol to determine the VAT, through the visual graphical analysis (loss of parallelism between the oxygen uptake and the carbon dioxide output). During CPET, before the end of each one-minute period, the subjects were asked to rate dyspnea (RPE-D) and leg fatigue (RPE-L) on the Borg CR-10 scale. After the VAT was determined, the score that the participants gave on the Borg CR1O scale was verified. CG participants showed higher workload, oxygen uptake, carbon dioxide output, ventilation and heart rate at the VAT compared to the G-DAC and G-DACb $(p<0.05)$. However, regarding the RPE-L and the RPE-D, no significant difference between the groups were observed $(p<0.05)$. Values between five and six on Borg CR-10 scale matched the VAT in the subjects studied. However, other parameters must be concomitantly used for prescribing exercise intensity in physical training protocols, at levels close to the VAT for patients with CAD.
\end{abstract}

Keywords | Coronary Disease; Exercise Test; Ratings of Perceived Exertion.
RESUMO I O objetivo do estudo foi identificar e comparar a percepção subjetiva do esforço (PSE) no limiar anaeróbio ventilatório (LAV) em indivíduos saudáveis e com doença arterial coronariana (DAC). Foram estudados 30 homens, sendo 10 saudáveis que constituíram o grupo controle (GC) e 20 diagnosticados com DAC, dos quais 10 faziam uso de medicamento betabloqueador (G-DACb) e 10 não faziam uso (G-DAC). Os voluntários foram submetidos a um teste de exercício cardiopulmonar (TECP) com protocolo contínuo tipo rampa para determinação do LAV, através da análise visual gráfica (perda do paralelismo entre o consumo de oxigênio e a produção de dióxido de carbono). Durante a realização do TECP, foi solicitado aos voluntários que relatassem ao final de cada minuto a percepção subjetiva do esforço de membros inferiores (PSE-M) e a percepção subjetiva do esforço respiratório (PSE-R), através da escala CR-10 de Borg. O GC apresentou maiores valores de potência, consumo de oxigênio, produção de dióxido de carbono, ventilação e frequência cardíaca no LAV comparado aos grupos G-DAC e G-DACb ( $p<0,05)$. A PSE-M foi menor no G-DACb comparado ao GC (p<0,05). Após ajuste pela covariável potência, não houve diferença significativa entre os grupos para PSE-M e PSE-R (p>0,05). Valores entre cinco e seis na escala CR-10 de Borg correspondeu ao LAV na amostra estudada. Entretanto, outros parâmetros devem ser utilizados concomitantemente para a prescrição da intensidade de exercício nos protocolos de treinamento físico, em níveis próximos ao LAV para pacientes com DAC.

Descritores | Doença das Coronárias; Teste de Esforço; Percepção Subjetiva de esforço.

Study conducted at the Laboratory of Cardiovascular Physical Therapy and Functional Tests of Universidade Metodista de Piracicaba (UNIMEP) - Piracicaba (SP), Brazil.

'Department of Physical Therapy, Universidade Federal de São Carlos (UFSCar) - São Carlos (SP), Brazil.

${ }^{2}$ Centro Universitário Adventista de São Paulo (UNASP) - Engenheiro Coelho (SP), Brazil

${ }^{3}$ School of Health Sciences, Universidade Metodista de Piracicaba (UNIMEP) - Piracicaba (SP), Brazil. 
RESUMEN I El objetivo del estudio fue identificar y comparar la percepción subjetiva del esfuerzo (PSE) en el liminar anaeróbico ventilatorio (LAV) en sujetos sanos y con enfermedad arterial coronaria (EAC). Fueron estudiados 30 hombres siendo10 sanos que constituyeron el grupo control (GC) y 20 diagnosticados con EAC, de los cuales 10 utilizaban medicamento betabloqueante (G-DACb) y 10 no utilizaban (G-DAC). Los voluntarios fueron sometidos a una prueba de ejercicio cardiopulmonar (TECP) con protocolo continuo tipo rampa para la determinación del LAV, a través del análisis gráfico visual (pérdida del paralelismo entre el consumo de oxígeno y producción de dióxido de carbono). Durante la realización del TECP, se pidió a los voluntarios que informaran al final de cada minuto la percepción subjetiva del esfuerzo de los miembros inferiores (PSE-M) y la percepción subjetiva del esfuerzo respiratorio
(PSE-R) a través de la escala de Borg CR-1O. El GC presentó mayores valores de potencia, consumo de oxígeno, producción de dióxido de carbono, ventilación y frecuencia cardiaca en el LAV comparado con los grupos G-DAC y G-DACb $(p<0,05)$. La PSE-M fue menor en el G-DACb comparado con el GC $(p<0,05)$. Después del ajuste por la covariable potencia, no hubo diferencia significativa entre los grupos para PSE-M y PSE-R ( $p>0,05)$. Los valores entre cinco y seis en la escala CR-10 de Borg correspondieron al LAV en la muestra estudiada. Sin embargo, otros parámetros deben ser utilizados simultáneamente para la prescripción de la intensidad del ejercicio en los protocolos de entrenamiento físico, en niveles cercanos al LAV para pacientes con EAC.

Palabras clave I Enfermedad Coronaria; Prueba de Esfuerzo; Percepción Subjetiva del Esfuerzo.

\section{INTRODUCTION}

A sedentary lifestyle has been considered the main modifiable risk factor for coronary artery disease $(\mathrm{CAD})^{1}$. On the other hand, regular physical exercise can reduce cardiac mortality from 20 to $30 \%$ along with lifestyle changes ${ }^{2}$. However, the dropout rate in physical conditioning programs and cardiac rehabilitation is approximately $45 \%{ }^{3}$.

One of the main problems related to adhering to physical exercise programs is the difficulty to achieve and maintain the intensity prescribed for training ${ }^{4}$. Workouts performed at an inadequate intensity can yield limited benefits and even be unfavorable, raising cardiovascular and orthopedic risks.

Some authors ${ }^{5}$ report that intensities close to the ventilatory anaerobic threshold (VAT), the level of physical exercise at which the production of energy by the aerobic metabolism is supplemented by the anaerobic metabolism ${ }^{6}$, are an indispensable parameter for effective training and are also safe in regards to potential cardiovascular events.

These observations have renewed the attention drawn toward the potential for alternative approaches and auxiliary tools, such as the rating of perceived exertion (RPE), used to prescribe and monitor exercise intensity in healthy individuals and those with cardiovascular disease $\mathrm{e}^{7,8}$.

The Borg CR-10 Scale is a scale composed of numbers related to verbal expression used to determine degrees of intensity, 7 . However, although some authors have determined RPE degrees at the moment of VAT in healthy individuals ${ }^{10,11}$, there is a scarcity of studies with individuals with $\mathrm{CAD}$ who use and do not use beta-blocker medication.

In other studies, researchers report that cardiac disease and the use of beta-blockers can induce alterations related to RPE, reducing tolerance to exercise and increasing the perception of effort about the same exercise intensity ${ }^{12-14}$. Thus, in the present study our purpose was to identify and compare the RPE values in relation to lower limbs (RPE-L) and dyspnea (RPE-D) at the moment of VAT between healthy individuals and patients with CAD who used and did not use beta-blocker medication. We also aimed at verifying the relation of ventilatory and metabolic variables and power in Watts (W) with RPE.

\section{METHODS}

\section{Participants}

The participants were 30 male individuals allocated in three groups. One group was composed by 10 volunteers with clinical diagnosis of CAD who did not use beta-blocker medication (CAD-G); the second group counted 10 volunteers who also had clinical diagnoses but used beta-blockers (CADb-G); and 10 healthy individuals who composed the control group (CG).

In the groups with $\mathrm{CAD}$, we included the volunteers who presented a reduction in coronary luminal diameter larger than or equal to $50 \%$ in at least one coronary artery, determined by a coronary angiogram ${ }^{15}$ and who had been submitted to angioplasty at least 3 months 
prior to the present study. Volunteers with osteomyoarticular diseases or disorders were excluded.

To be included in the CG, the individuals had to present normal results in the biochemical exams and in an electrocardiogram (ECG); they could not have cardiovascular, respiratory, osteomyoarticular and metabolic diseases; make no use of any type of medication; and not consume tobacco, alcohol or drugs that caused chemical dependence.

This study was approved by the Ethics Committee of the institution in question. Only the individuals who signed the Informed Consent form were included.

\section{Procedures}

The experimental procedures were conducted in a climatized laboratory, with the temperature and relative air humidity maintained at approximately $23^{\circ} \mathrm{C}$ and $60 \%$, respectively. The volunteers were familiarized with the laboratory and the experimental protocol the day before the test. On the day of the test, they were asked about their health condition and whether they had followed the recommendations to avoid the ingestion of alcoholic or stimulating beverages (coffee, tea, soda) and extenuating physical exercises. Before the protocol was carried out, the volunteers remained in the supine position for 15 minutes so that their blood pressure, heart rate (HR) and ECG at rest could be measured with the purpose of verifying whether their basal conditions were satisfactory to carry on with the experiment. We considered as unsatisfactory conditions alterations in blood pressure and/or HR in comparison to the rates obtained on the day of familiarization, or the presence of alterations or abnormalities on the ECG.

\section{Experimental protocol}

The experiment consisted of a cardiopulmonary exercise test (CPET) with a continuous ramp protocol, performed on a cycle ergometer with electromagnetic brakes (Quinton Corival 400) and adjusted seat so as to allow for about 5 to $10^{\circ}$ of knee flexion. The volunteers were instructed to maintain their pedaling rate at 60 rotations per minute (rpm) and to not perform isometric contraction of their upper limbs during the test.

The CPET consisted of 1 minute of rest on the cycle ergometer in the sitting position, followed by 4 minutes of warm-up pedaling at $4 \mathrm{~W}$ of power. The power was increased per minute up to physical exhaustion, defined as the moment when the volunteers were no longer able to maintain their pedaling rate at $60 \mathrm{rpm}$, or until the manifestation of any limiting symptom. The increments in power were determined for each individual according to the formula proposed by Wasserman et al. ${ }^{6}$ :

$$
\operatorname{Power}(W)=\frac{[(\text { height }- \text { age }) .14]-[150+(6 . \text { body mass })]}{100}
$$

\section{Electrocardiogram and heart rate recording}

During the CPET, the ECG and the CG were registered beat-by-beat by a single-channel cardiac monitor and processed with an analog-to-digital converter that acted as an interface between the cardiac monitor and a computer. The ECG was also registered in real time using the device and software CardioPerfect ${ }^{\circledR}$.

\section{Recording ventilatory and metabolic variables}

The ventilatory and metabolic variables oxygen consumption $\left(\mathrm{VO}_{2}\right)$, carbon dioxide production $\left(\mathrm{VCO}_{2}\right)$, and ventilation (VE) were obtained with each breath throughout the CPET with a system that measures expired gases (CPX/D, Medical Graphics), duly calibrated before each test. Three trained observers identified the VAT using a visual graphical method to estimate disproportionate $\mathrm{VCO}_{2}$ increases based on the linear increase of $\mathrm{VO}_{2}{ }^{16,17}$. This method was based on the V-Slope method described by Beaver et al. ${ }^{17}$. The VAT was considered as the average of the data obtained from the analyses of the three observers ${ }^{16,17}$.

\section{The Borg CR-10 Scale}

During the familiarization session, each volunteer received instructions about the use of the Borg CR-10 $\mathrm{Scale}^{18}$. On the course of the CPET, we asked the participants to report their RPE-L and RPE-D at the end of each minute according to the scale ${ }^{18}$. After determining the VAT, the value provided by the volunteers on the Borg CR-10 Scale was compared.

\section{Statistical analysis}

For the continuous variables, an intergroup comparison was conducted through One-way ANOVA 
and Tukey's post hoc. For the discrete variables, we used Kruskal-Wallis' and Dunn's post hoc. Effect size (ES) was determined by Cohen's $\mathrm{F}^{19}$ and classified as small effect $(\mathrm{ES}=0.10)$, moderate effect $(\mathrm{ES}=0.25)$ and large effect $(\mathrm{ES}=0.40)$. The analysis of covariance (ANCOVA) was used for the intergroup comparison of the variables RPE-L and RPE-D considering the variable power as a covariate. Bonferroni's correction was applied to the multiple comparisons of the averages adjusted by ANCOVA. The relation of the variables power, $\mathrm{VO}_{2}$ and $\mathrm{HR}$ with RPE-L and RPE-R was verified through Spearman's correlation coefficient. The level of significance established was $5 \%$.

\section{RESULTS}

The participants' age, anthropometric and basal hemodynamic characteristics are displayed on Table 1. We verified that the body mass index was lower in the CG compared to the CAD-G, while HR was lower in the $\mathrm{CADb}-\mathrm{G}$ group compared to the CAD-G. However, no significant differences were found in regards to the other variables.

Table 2 displays the values of the variables obtained at the peak of the CPET and at the moment of VAT. Both at the peak and at moment of VAT, the volunteers in the $\mathrm{CG}$ presented higher values of power, $\mathrm{VO}_{2}, \mathrm{VE}$ and $\mathrm{HR}$ in comparison to the $\mathrm{CAD}-\mathrm{G}$ and the CADb-G $(\mathrm{p}<0.05)$.
Also at the peak of the CPET, the CAD-G presented higher HR when compared to the CADb-G ( $<<0.05)$. In regards to the RPE-L, the $\mathrm{CG}$ reached higher levels when compared to the CADb-G $(p<0.05)$ both at the peak and the VAT. In its turn, the RPE-D was not significantly different among the groups $(p>0.05)$. The analysis of $\mathrm{ES}$ revealed a large effect $(>0.4)$ concerning all variables analyzed, with exception of the RPE-D, corroborating the results of the comparative analyses.

The ANCOVA did not reveal any significant differences among the groups pertaining to the variable RPE-L at peak $\left(\mathrm{F}=0.12 ; \mathrm{p}=0.88\right.$; partial $\left.\eta^{2}=0.01\right)$ and at the VAT $\left(\mathrm{F}=1.21 ; \mathrm{p}=0.31 ;\right.$ partial $\left.\eta^{2}=0.08\right)$. In addition, we did not

Table 1. Age and anthropometric and basal hemodynamic characteristics of the control group, coronary artery disease group that did not use beta-blocker medication, and individuals with coronary arterial disease who used beta-blocker medication

$\begin{array}{lccc}\text { Age } & \begin{array}{c}\text { CG } \\ (n=10)\end{array} & \begin{array}{c}\text { CAD-G } \\ (n=10)\end{array} & \begin{array}{c}\text { CADb-G } \\ (n=10)\end{array} \\ \text { Body mass }(\mathrm{kg}) & 53.4 \pm 3.7 & 56.3 \pm 5.4 & 56.1 \pm 9.3 \\ \text { Height }(\mathrm{cm}) & 71.4 \pm 7.9 & 78.9 \pm 16.3 & 79.8 \pm 13.3 \\ \text { BMl }\left(\mathrm{kg} / \mathrm{m}^{2}\right) & 170.2 \pm 5.6 & 167.6 \pm 7.2 & 168.7 \pm 8.7 \\ \text { SBP }(\mathrm{mmHg}) & 24.5 \pm 1.7^{*} & 28.1 \pm 4.2 & 27.9 \pm 2.6 \\ \text { DBP }(\mathrm{mmHg}) & 117 \pm 9.5 & 127 \pm 9.5 & 127 \pm 23.6 \\ \text { RR (rpm) } & 76 \pm 5.2 & 81.7 \pm 8.7 & 78 \pm 16.9 \\ \text { HR (bpm) } & 15 \pm 2 & 14 \pm 2 & 16 \pm 3 \\ \text { Beta-blocker user } & 66 \pm 6 & 68 \pm 7 & 59 \pm 6^{\dagger} \\ \text { no } & \text { no } & \text { no } & \text { yes }\end{array}$

*p<0.05 CG versus CAD-G; ‘p<0.05 CADb-G versus CAD-G ; BMI: body mass index; SBP: systolic blood pressure; DBP: diastolic blood pressure; HR: heart rate; CG: control group; CAD-G: coronary arterial disease group; CADb-G: coronary arterial disease group with users of beta-blockers:

RR: respiratory rate: HR: heart rate. Values in mean \pm standard deviation

Table 2. Variables obtained on the test of cardiopulmonary exercise at the moment when the ventilatory anaerobic threshold was reached and at the peak of exercise in the groups control, individuals with coronary arterial disease who did not use beta-blocker medication, and those who used beta-blocker medication

\begin{tabular}{|c|c|c|c|c|c|c|}
\hline & $\begin{array}{c}\text { CG } \\
(n=10)\end{array}$ & $\begin{array}{l}\text { CAD-G } \\
(n=10)\end{array}$ & $\begin{array}{l}\text { CADb-G } \\
(n=10)\end{array}$ & F value & p-value & Effect size \\
\hline \multicolumn{7}{|l|}{ PEAK } \\
\hline Power (W) & $156.5 \pm 23.9^{\star+}$ & $113.3 \pm 18.2$ & $94.0 \pm 23.8$ & 20.9 & $<0.001$ & 1.2 \\
\hline $\mathrm{VO}_{2}(\mathrm{~mL} / \mathrm{kg} / \mathrm{min})$ & $26.2 \pm 5.1^{\star \dagger}$ & $18.6 \pm 3.9$ & $15.9 \pm 3.4$ & 16.2 & $<0.001$ & 1.0 \\
\hline $\mathrm{VCO}_{2}(\mathrm{~L} / \mathrm{min})$ & $2.0 \pm 0.3^{\star \dagger}$ & $1.5 \pm 0.2$ & $1.2 \pm 0.3$ & 17.6 & $<0.001$ & 1.1 \\
\hline VE (L/min) & $59.7 \pm 13.9^{\star \dagger}$ & $43.5 \pm 9.1$ & $37.6 \pm 9.4$ & 10.7 & $<0.001$ & 0.9 \\
\hline HR (bpm) & $155.5 \pm 8.9^{\star+}$ & $132.9 \pm 18.2^{\dagger}$ & $105.1 \pm 17.0$ & 27.2 & $<0.001$ & 1.6 \\
\hline RPE-L & $7.5 \pm 1.1^{+}$ & $6.6 \pm 1.6$ & $6.0 \pm 0.8$ & 4.0 & 0.03 & 0.2 \\
\hline RPE-D & $6.6 \pm 1.3$ & $6.2 \pm 1.5$ & $5.8 \pm 0.8$ & 1.0 & 0.4 & 0.3 \\
\hline \multicolumn{7}{|l|}{ VAT } \\
\hline Power (W) & $124.1 \pm 25.6^{\star t}$ & $84.2 \pm 27.4$ & $77.7 \pm 20.9$ & 10.3 & $<0.001$ & 0.8 \\
\hline $\mathrm{VO}_{2}(\mathrm{~mL} / \mathrm{kg} / \mathrm{min})$ & $21.1 \pm 5.5^{\star \dagger}$ & $14.4 \pm 4.7$ & $13.6 \pm 3.4$ & 7.9 & 0.002 & 0.7 \\
\hline $\mathrm{VCO}_{2}(\mathrm{~L} / \mathrm{min})$ & $1.4 \pm 0.3^{* \dagger}$ & $1.0 \pm 0.3$ & $1.0 \pm 0.2$ & 6.3 & 0.005 & 0.7 \\
\hline VE (L/min) & $39.2 \pm 10.9^{*+}$ & $28.5 \pm 8.4$ & $28.5 \pm 7.5$ & 4.7 & 0.02 & 0.6 \\
\hline HR (bpm) & $131.1 \pm 8.5^{\star \dagger}$ & $112.8 \pm 18.8$ & $97.4 \pm 17.7$ & 11.5 & $<0.001$ & 0.9 \\
\hline RPE-L & $6.5 \pm 1.5^{\dagger}$ & $5.9 \pm 1.6$ & $4.9 \pm 1.3$ & 3.3 & 0.06 & 0.5 \\
\hline RPE-D & $5.5 \pm 1.5$ & $5.4 \pm 1.7$ & $5.0 \pm 1.3$ & 0.3 & 0.8 & 0.1 \\
\hline
\end{tabular}

${ }^{*} \mathrm{p}<\mathrm{O} .05$ versus CAD-G; ${ }^{\dagger}$ p $<0.05$ versus CADb-G; $\mathrm{VO}_{2}$ : oxygen consumption; $\mathrm{VCO}_{2}$ : carbon dioxide production; VE: ventilation; HR: heart rate; RPE-L: rating of perceived exertion - lower limbs; RPE-D: rating of perceived exertion - dyspnea; CG: control group; CAD-G: coronary arterial disease group; CADb-G: coronary arterial disease group with users of beta-blockers; VAT: ventilatory anaerobic threshold. Values shown in mean \pm standard deviation 
identify any significant differences concerning the variable RPE-D at peak $\left(F=0.07 ; p=0.93\right.$; partial $\left.\eta^{2}=0.006\right)$ and at the VAT $\left(F=0.14 ; p=0.87\right.$; partial $\left.\eta^{2}=0.01\right)$.

Significant correlations were found between power, $\mathrm{VO}_{2}, \mathrm{HR}$ and RPE. We also observed a linear decrease of the RPE-L and RPE-D in all groups (Table 3 and Figure 1).

\section{DISCUSSION}

In the present study, our purpose was to identify and compare the values of RPE-L and RPE-D obtained at the VAT moment in healthy individuals and patients with CAD who used and did not use beta-blocker medication, as well as to verify the relation of the ventilatory and metabolic variables and power with RPE.

The results of the present study show that the CG presented higher values of power and of metabolic and ventilatory variables in comparison to the groups CAD and CADb-G. However, regarding the RPE-L, the $\mathrm{CADb}-\mathrm{G}$ showed lower VAT and peak effort values compared to the CG. These findings disagree with previous studies ${ }^{14,20}$ in which the authors observed an increase in RPE after the use of beta-blocker medication. The lower values found in the CADb-G can be justified by the significant difference in the intensity of effort achieved by the groups at the moment of VAT. Recent studies have proposed that the physiological bases to explain the RPE are consistent with the theory of reafferent corollary discharge ${ }^{21,22}$. According to this theory, an increase in central motor commands is responsible for inciting the muscular activity necessary to meet the demands of the activity in progress. This increase in muscle activation results in an increase in the shots released by neuromuscular joints, thus promoting feedback in the sensory areas of the brain, where this information is processed and RPE originates. Thus, the more intense the effort, the higher the RPE.

Another factor that must be considered in regards to the lack of difference in RPE among the groups is the fact that these comparisons were carried out at specific physiological moments, such as when the VAT was reached and at the peak of effort. Previous studies, in which the authors verified the influence of beta-blockers on RPE, the parameters of comparison used were pre-established intensities or a percentage determined in relation to maximum $\mathrm{VO}_{2}{ }^{13,20.23}$.

With the purpose of eliminating the influence of different intensities on RPE, achieved at the VAT and at the peak of effort, we conducted the ANCOVA considering power as a covariate. After the adjustment, the
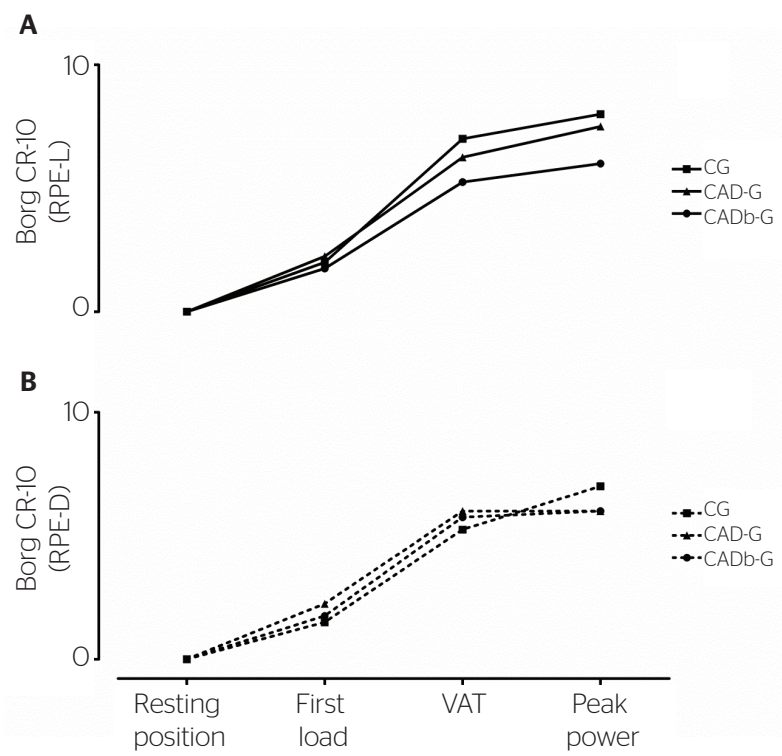

RPE-L: rating of perceived exertion - lower limbs; RPE-D: rating of perceived exertion - dyspnea; CG: control group; CAD-G: coronary arterial disease group; CADb-G: coronary arterial disease group with users of beta-blockers; VAT: ventilatory anaerobic threshold

Figure 1. Rating of perceived exertion of lower limbs and dyspnea in the resting position, at the first increase in load, at the ventilator anaerobic threshold, and peak power of the groups control, coronary artery disease group without beta-blockers, and coronary artery disease group with users of beta-blockers

Table 3. Spearman's correlation coefficients

\begin{tabular}{|c|c|c|c|c|c|c|c|}
\hline \multirow{2}{*}{ Variables } & \multirow{2}{*}{ RPE } & \multicolumn{2}{|c|}{ CG } & \multicolumn{2}{|c|}{ CAD-G } & \multicolumn{2}{|c|}{ CADb-G } \\
\hline & & $r_{s}$ & $\mathrm{p}$-value & $r_{s}$ & $\mathrm{p}$-value & $r_{s}$ & $\mathrm{p}$-value \\
\hline \multirow[t]{2}{*}{$\mathrm{VO}_{2}(\mathrm{~mL} / \mathrm{kg} / \mathrm{min})$} & LL & 0.74 & $<0.0001$ & 0.77 & $<0.0001$ & 0.70 & $<0.0001$ \\
\hline & Dyspnea & 0.79 & $<0.0001$ & 0.74 & $<0.0001$ & 0.56 & $<0.0001$ \\
\hline \multirow[t]{2}{*}{ HR (bpm) } & LL & 0.82 & $<0.0001$ & 0.72 & $<0.0001$ & 0.61 & $<0.0001$ \\
\hline & Dyspnea & 0.84 & $<0.0001$ & 0.70 & $<0.0001$ & 0.48 & $<0.0001$ \\
\hline \multirow[t]{2}{*}{ Power (W) } & LL & 0.80 & $<0.0001$ & 0.79 & $<0.0001$ & 0.73 & $<0.0001$ \\
\hline & Dyspnea & 0.84 & $<0.0001$ & 0.74 & $<0.0001$ & 0.64 & $<0.0001$ \\
\hline
\end{tabular}

RPE: rating of perceived exertion; CG: control group; CAD-G: coronary arterial disease group; CADb-G: coronary arterial disease group with users of beta-blockers; $\mathrm{VO}_{2}$ : oxygen consumption; HR: heart rate; LL: lower limbs 
results did not show significant differences among the groups concerning RPE-L and RPE-D, which suggests that the use of beta-blocker medication did not influence RPE at the same level of intensity.

The influence of beta-blockers in RPE is a controversial topic. Although several authors have found that the use of beta-blocker medication promotes an increase in $\mathrm{RPE}^{13,20.23}$, other researchers have observed that this influence was absent ${ }^{14,24}$, which is in agreement with the findings of the present study.

The comparison of RPE at the moment of VAT and the present findings corroborate the results of previous studies $^{10.11,25,26}$, in which the authors also observed similar RPE values at the anaerobic threshold of individuals with different characteristics, such as gender ${ }^{10}$ and level of physical activity ${ }^{11,25}$.

Another important finding in our study pertains to the significant correlations of power, $\mathrm{VO}_{2}$ and $\mathrm{HR}$ with RPE-L and RPE-D, as they confirm the association of $\mathrm{RPE}$ with cardiopulmonary responses and workout intensity. These findings corroborate those of Felts et al. ${ }^{26}$, who found a significant relation between RPE and workout load and duration. However, it is important to highlight that the correlations found in the $\mathrm{CADb}-\mathrm{G}$ were not as strong as those found in the other groups. These findings can be explained by the effects of beta-blockers in reducing myocardial contractility, cardiac output and HR during physical exercises ${ }^{27}$. Thus, the maintenance of a cardiac output that is adequate and compatible with the intensity of effort depends on compensatory adjustments in the circulatory system, such as an increase in stroke volume. This justifies the less marked association between RPE and the variables $\mathrm{VO}_{2}$ and $\mathrm{HR}$ in this group.

Another important aspect is the necessity of parameters to advise cardiopathic patients in regards to the unsupervised practice of physical exercise after discharge. Chow and Wilmore ${ }^{28}$ verified the accuracy of using physiological parameters to maintain $\mathrm{HR}$ in a pre-established workout zone by testing three experimental situations. In the first, the individuals were asked to run without feedback from the researchers. They were responsible for controlling their own gait cadence. On their own, they were able to remain in the HR zone only $25 \%$ of the time. In the second situation, the volunteers were allowed to check their HR periodically, which raised the rate of permanence in the training zone to $55 \%$. In the third experimental condition, the participants were informed about the RPE corresponding to the training zone. A permanence rate of $48 \%$ was observed, not different from the accuracy reached by monitoring $\mathrm{HR}$.

Thus, by determining the RPE that corresponds to the VAT, it is possible to have a safe parameter that complements HR monitoring and other previous orientations for these patients' supervised and unsupervised training 8,29 .

Although the interesting results obtained in the present study are a starting point for future investigations, some limitations should be considered. Even though producing a target RPE based on a test of increasing effort is a valid method to prescribe workout intensity ${ }^{30-32}$, in this study we did not apply long protocols with constant loads. Therefore, more studies are necessary to verify whether the time taken to perform a physical activity influences RPE, and whether the physiological response that corresponds to a certain RPE value in an incremental test differs from values achieved on the course of constant intensities of training.

In conclusion, the results show that the individuals with CAD, users and non-users of beta-blockers, have a similar RPE to that of healthy individuals at the level of VAT for the same relative power. Thus, values between five and six on the Borg CR-10 scale correspond to intensity levels close to the VAT in the sample studied and can be used as parameters that are complementary to HR monitoring when prescribing workout intensity on the physical training protocols of these individuals.

\section{REFERENCES}

1. Thompson PD, Buchner D, Pina IL, Balady GJ, Williams MA, Marcus BH, et al. Exercise and physical activity in the prevention and treatment of atherosclerotic cardiovascular disease: a statement from the Council on Clinical Cardiology (Subcommittee on Exercise, Rehabilitation, and Prevention) and the Council on Nutrition, Physical Activity, and Metabolism (Subcommittee on Physical Activity). Circulation. 2003:107(24):3109-16.

2. Hämäläinen H, Luurila OJ, Kallio V, Knuts LR, Arstila M, Hakkila J. Longterm reduction in sudden deaths after multifactorial intervention programme in patients with myocardial infarction: 10-year results of a controlled investigation. Eur Heart J. 1989;10(1):55-62.

3. Franklin BA. Program factors that influence exercise adherence: practical adherence skills for the clinical staff. In: Dishman RK, editors. Exercise Adherence: Its Impact on Public Health. Champaign: Human Kinetics Publishers; 1988. p. 237-58.

4. Dishman RK. Prescribing exercise intensity for healthy adults using perceived exertion. Med Sci Sports Exerc. 1994;26(9):1087-94.

5. Sirol FN, Sakabe DI, Catai AM, Milan LA, Martins LEB, Silva E. Comparison of power output and heart rate levels in anaerobic threshold determinations by two indirect methods. Braz J Phys Ther. 2005;9(2):211-218. 
6. Wasserman K, Hansen JE, Sue D, Whipp BJ, Casaburi R. Principles of exercise testing and interpretation. Philadelphia: Williams and Wilkins; 1999.

7. Borg E, Kaijser L. A comparison between three rating scales for perceived exertion and two different work tests. Scand J Med Sci Sports. 2006:16(1):57-69.

8. Godoy M, Bellini AJ, Passaro LC, Mastrocolla LE, Sbissa AS, Araujo CGS, et al. I Consenso Nacional de Reabilitação Cardiovascular. Arq Bras Cardiol. 1997;69(4):267-91.

9. Borg GAV. Psychophysical bases of perceived exertion. Med Sci Sports Exerc. 1982;14(5):377-81.

10. Purvis JW, Cureton KJ. Ratings of perceived exertion at the anaerobic threshold. Ergonomics. 1981;24(4):295-300.

11. Zamunér AR, Moreno MA, Camargo TM, Graetz JP, Rebelo ACS, Tamburús NY, et al. Assessment of subjective perceived exertion at the anaerobic threshold with the Borg CR-1O scale. J Sports Sci Med. 2011:10(1):130-6.

12. Barmeyer A, Meinertz T. Anaerobic threshold and maximal oxygen uptake in patients with coronary artery disease and stable angina before and after percutaneous transluminal coronary angioplasty. Cardiology. 2002;98(3):127-31.

13. Derman WE, Sims R, Noakes TD. The effects of anti-hypertensive medications on the physiological response to maximal exercise testing. Pharmacology. 1992:19(Suppl 5):S122-7.

14. Van Bortel LM, van Baak MA. Exercise tolerance with nebivolol and atenolol. Cardiovasc Drugs Ther. 1992;6(3):239-47.

15. César, LAM (ed.). Diretrizes de doença coronariana crônica angina estável. Arq Bras Cardiol. 2004;83(Suppl 2):1-43.

16. Higa MN, Silva E, Neves VF, Catai AM, Gallo L Jr, Silva de Sá MF. Comparison of anaerobic threshold determined by visual and mathematical methods in healthy women. Braz J Med Biol Res. 2007:40(4):501-8.

17. Beaver WL, Wasserman K. Whipp BJ. A new method for detecting anaerobic threshold by gas exchange. J Appl Physiol. 1986;60(6):2020-7.

18. Borg G. Borg's perceived exertion and pain scales. Ilinois: Human Kinetics; 1998.
19. Cohen J. Statistical power analysis for the behavioral sciences. $2^{\mathrm{a}}$ ed. New York: Lawrence Erlbaum Associates; 1988.

20. Eston RG, Thompson M. Use of ratings of perceived exertion for predicting maximal work rate and prescribing exercise intensity in patients taking atenolol. Br J Sports Med. 1997;31(2):114-9.

21. Marcora S. Perception of effort during exercise is independent of afferent feedback from skeletal muscles, heart, and lungs. J Appl Physiol. 2009;106:2060-2.

22. Morree HM, Klein C, Marcora SM. Perception of effort reflects central motor command during movement execution. Phychophysiology. 2012;49(9):1242-53.

23. Pearson SB, Banks DC, Patrick JM. The effect of $\beta$-adrenoceptor blockade on factors affecting exercise tolerance in normal man. $\mathrm{Br} \mathrm{J}$ Clin Pharmac. 1979;8(2):143-8.

24. Eston RG, Connolly D. The use of ratings of perceived exertion for exercise prescription in patients receiving beta-blocker therapy. Sports Med. 1996;21(3):176-90.

25. Garcin M, Mille-Hamard L, Billat V. Influence of aerobic fitness level on measured and estimated perceived exertion during exhausting runs. Int J Sports Med. 2004;25(4):270-7.

26. Felts WM, Crouse S, Brunetz M. Influence of aerobic fitness on ratings of perceived exertion during light to moderate exercise. Percept Mot Skills. 1988;67(2):671-6.

27. Cohn JN. Clinical implications of the hemodynamic effects of beta blockade. Am J Cardiol. 1985;55(10):125D-128-D.

28. Chow RJ, Wilmore JH. The regulation of exercise intensity by ratings of perceived exertion. J Cardiopulm Rehabil. 1984;4:382-7.

29. Oliveira Filho JA, Leal AC, Lima VC, Santos Filho DV, Luna Filho B. Unsupervised rehabilitation: effects of exercise training over the long run. Arq Bras Cardiol. 2002;79(4):239-44.

30. Eston RG, Williams JG. Reliability of ratings of perceived effort regulation of exercise intensity. Br J Sports Med. 1988;22(4):153-5.

31. Smutok MA, Skrinar GS, Pandolf KB. Exercise intensity: subjective regulation by perceived exertion. Arch Phys Med Rehabil. 1980;61(12):569-74.

32. Dunbar CC, Robertson RJ, Baun R, Blandin KM, Metz K, Burdett R, et al. The validity of regulating exercise intensity by ratings of perceived exertion. Med Sci Sports Exerc. 1992;24(1):94-9. 